\title{
Antinomias pós-modernas sobre a natureza
}

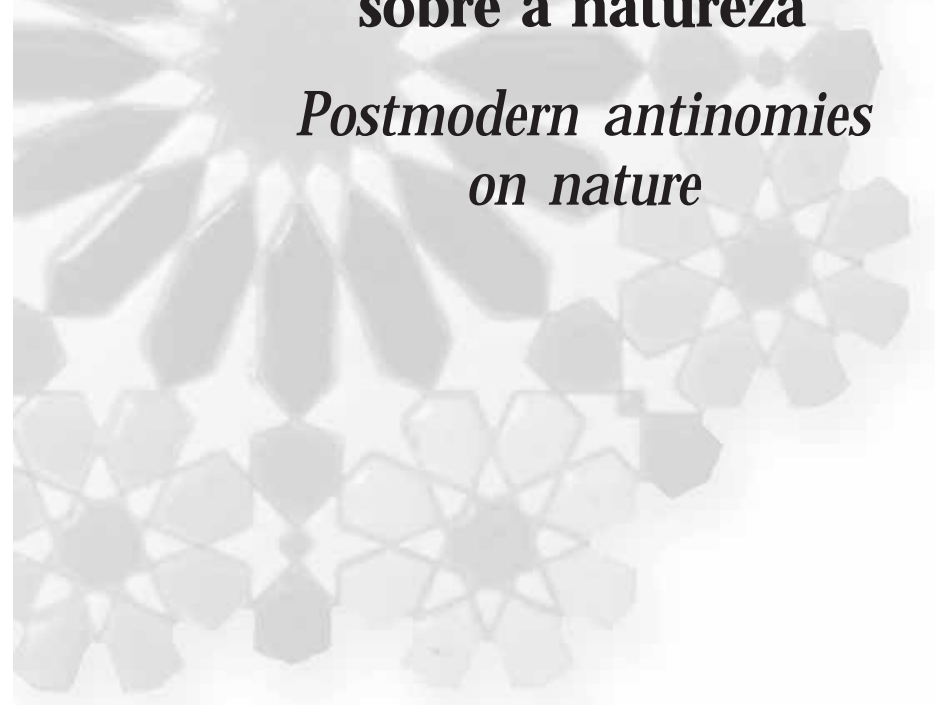

José M arcos Froehlich

Professor do Departamento e do Programa de Pós-graduação em Extensão Rural/ Universidade Federal de Santa Maria.

Universidade Federal de Santa Maria - DEAER-CCR - Campus Camobi 97105-900 - Santa Maria - RS - Brasil jmarcos.froehlich@pq.cnpq.br

\section{Celso Reni Braida}

Professor do Departamento e do Programa de Pós-graduação em Filosofia/Universidade Federal de Santa Catarina.

Universidade Federal de Santa Catarina - Departamento de Filosofia - CFH - Campus Universitário 88010-970 - Florianópolis - SC - Brasil braida@cfh.ufsc.br

Recebido para publicação em janeiro de 2008. Aprovado para publicação em março de 2010.

FROEHLICH, José Marcos; BRAIDA, Celso Reni. Antinomias pós-modernas sobre a natureza. História, Ciências, Saúde - Manguinhos, Rio de Janeiro, v.17, n.3, jul.-set. 2010, p.627-641.

\section{Resumo}

Analisa o vínculo intrínseco entre a elaboração moderna de ciência e a noção de natureza a ela subjacente. Discute as características das posições pós-modernas e inventaria as ideias recorrentes de natureza nas diferentes épocas históricas. Problematiza indicadores de incongruências nas imagens pós-modernas da natureza. Por meio da análise e história conceitual, explicita pontos de tensão nas proposições teóricas pós-modernas em relação às diferentes noções de natureza. Sugere que a equivocidade da noção de natureza produz múltiplos paradoxos e antinomias no pensamento contemporâneo, muitos dos quais tiveram emergência no âmbito da própria modernidade e tornaram-se ainda mais explícitos e intensos na conjuntura tecnocientífica do mundo atual.

Palavras-chave: natureza; ciência; pós-modernidade.

\section{Abstract}

This article analyzes the intrinsic link between the modern view of scienceand its underlying idea of nature. After discussing the characteristics of the postmodern positions and summarizing the various conceptions of nature prevalent at different times throughout history, we problematize indicators of incongruity in postmodern images of nature. Our objective, through analysis and conceptual history, is to delineate the points of tensions concerning different notions of nature within postmodern theories. Wethen suggest that the equivocality of the concept of nature produces multiple paradoxes and antinomies in contemporary thought, many of which emerged within the scope of modernity itself, becoming even more explicit and intense in the current technical and scientific climate.

Keywords: nature; science; postmodernism. 


\begin{abstract}
A consciência desi mesmo é, pois, simplesmente uma função da matéria organizada - e, em grau mais adiantado, essa função se volta contra seu próprio portador, converte-se em tendência a aprofundar ea explicar o fenômeno que provocou: uma tendência cheia às vezes de promessas e de desesperação, da vida a conhecerse a si mesma - investigação vã atéo último extremo, uma vez que a natureza não possa se resolver na consciência, nem a vida possa surpreen der aúltima palavra desi mesma.
\end{abstract}

(Thomas Mann, A montanha mágica)

Embora seja uma das noções mais recorrentes nas produções socioculturais da humanidade através dos tempos, 'natureza' é um daqueles conceitos cuja polissemia é tão eloquente quanto o grau de complexidade que envolve a dificuldade de se encontrar uma definição consensual. Em nossa época, tal dificuldade toma magnitude expressiva, pois vivemos sob uma intensa produção discursiva que aponta para as múltiplas ameaças que pairam sobre a natureza, traduzidas nos termos de uma crise ambiental de alcance global e sem precedentes na história humana. As múltiplas concepções de natureza e as relações históricas da humanidade com ela tornam-se objeto permanente de dúvidas e reflexões. Especula-se cada vez mais sobre a urgência e as possi bilidades de novas construções sobre a noção de natureza, mas elas não podem avançar sem a crítica e superação da narrativa elaborada sobre a natureza no pensamento que engendrou a ciência moderna (Schäfer, 1993; Videira, 2004; Mutschler, 2008).

A modernidade pode ser vista como a afirmação de si do sujeito que submete a (sua) natureza às regras da razão por meio da ciência e da técnica. Afirmação e não ciência de si, pois a ideia mesma de ciência era pensada inicial mente apenas como ciência 'da natureza'. Esse modelo permanece ainda, certamente, com grande vigor. Porém, o campo das ciências humanas e sociais conseguiu se impor e tornou-se presente a partir do final do século XIX, passando atualmente a questionar tanto a ideia moderna de ciência quanto a noção de natureza a ela subjacente. Ou seja, tanto o privilégio do sujeito quanto a posição da natureza inscritos no pensamento moderno são revisados pelo próprio movimento de autonomização das ciências humanas. Todavia, as concepções de natureza, ciência e cultura ainda contêm resquícios que produzem, no mais das vezes, mais confusão que esclarecimento.

Entre as características marcantes do pensamento moderno estavam a ideia do caráter matemático-determinístico da natureza, expresso na noção de lei natural, e a de liberdade da vontade ou espontaneidade da razão. Daí se seguiam que a ciência era um produto da razão humana, logo, da liberdade e que a natureza era conhecível justamente pela sua determinidade. No século XVII a consciência culta podia falar em termos de dignidade superior do homem em relação à natureza, separando a ordem dos instintos e causas e a ordem da razão. ${ }^{1}$ Uma coisa seria a razão e o sujeito, outra a natureza e o objeto. Um lado era marcado pela legalidade da liberdade, o outro, pela determinatividade da causalidade. No final do século XVIII, Kant (1980, p.XIII) podia ainda dizer imperiosamente que "a 
razão só compreende o que ela mesma produz segundo seu projeto, que ela teria de ir à frentecom princípios dos seus juízos segun do leis constantes e obrigar a natureza a responder às suas perguntas, mas sem se deixar conduzir por ela como se estivesse presa a um laço". Nessa perspectiva, a natureza é propriamente um produto da razão humana, e os valores e sentidos são apenas dessa e para essa razão.

Nesse modo de compreensão, o fundamento, a estrutura e a validação do conhecimento tinham sua raiz 'fora' da natureza investigada pela ciência, pois nessa concepção o que ficava de fora era a própria natureza do seu sujeito, visto que ele mesmo era pensado como pura razão, como não sendo natureza. A frase de Bacon de Verulamio, citada por Kant, é reveladora: "De nobis ipsis silemus" (De nós mesmos silenciamos). E Hegel (1989, p.59; tradução livre), o mestre de Marx, explicita: “O homem aparece depois da criação da natureza e constitui o oposto ao mundo natural. É o ser que se eleva ao segundo mundo. Temos em nossa consciência universal dois reinos: o da natureza e o do espírito. O réno do espírito é o criado pelo homem".

Embora estejamos muito distantes daquela época, a recusa da natureza e a afirmação do sujeito ainda orientam o debate atual (pós-moderno) sobre a ciência e a natureza. A suposição é de que a natureza, assim como a ciência da natureza, nada pode nos dizer; não podem ser a base da cultura, uma vez que são construções e produtos do sujeito. Tal pensamento encontra-se difuso nos mais diversos âmbitos e ramos das ciências humanas e sociais:

Mesmo aceitando-se a pressuposição de que o mundo natural - de natureza cósmica éregido por leis biofísi cas imutáveis, [inal cançáveis ao pensamento humano] o mundo natural apropriado pela cultura humana epela linguagem érelativo a esta cultura. Nossa percepção da realidade biofísica é relativa à cultura que nos socializou, portanto, é diferenciadae relativizada por estes val ores culturais. Temos por pressuposto quea realidade humanaéuma realidadecultural mente construída. ... No contexto desta problematização, reconhece-se que a dinâmica das estruturas biofísicas éinterpretada cultural mente, seja pela ciência, seja por outras instâncias da cultura. As ideias de natureza e o mundo natural, neste sentido, tornam-se pressupostos de teorias e ações políticas e técnicas. Em resumo: seja na tradição marxista ou em outras tradições das ciências sociais en aturais, a natureza e o mundo natural não podem ser tomados como dados. Romper com esta tradição positivista e essencial ista requer que estes conceitos sejam reconhecidos como passíveis de ressignificação em um processo de construção social da real idade natural, sendo, portanto, um produto do trabal ho e do conhecimento humano (Moreira, 2003, p.16-17).

Ora, a separação entre cultura e natureza e a suposição de que a natureza e o mundo natural não são dados, mas sim construtos e interpretações relativas a um sujeito social, não são senão a concepção moderna anterior à destranscendentalização do sujeito do conhecimento operada pelas ciências humanas a partir do século XIX. O passo propriamente pós-moderno foi a passagem da ideia de construção para a de 'invenção'. Nesse passo, porém, a própria ideia de ciência tem de ser abandonada. Por isso, um passo atrás agora parece não apenas promissor, mas antes necessário:

Mas tem havido um gran de número de artigos sobreo pós-modernismo, queconsidera a rel ação humana com a natureza. Isso é uma coisa muito boa. Quero dizer que, por 
muito tempo, a ciência social ignorou a natureza. Deixamos a natureza fora de nossos paradigmas. Pretendemos desenvolver paradigmas sobre comportamento humano, mas sem considerar a natureza como al go central. Isto é errado, pois nós produzi mos o dualismo entrea natureza ecultura. Mudançasna natureza, como a bioengenharia, afetam o que somos cultural mente. Está cada vez mais difícil fazer a separação. As tecnologias de reprodução estão afetando quem somos nós. Assim, a idéia de que há uma natureza e uma cultura separadas revel a-se cada vez menos apropriada (Redclift, 1996, p.12).

A revisão do pensamento sobre a relação entre natureza e cultura, todavia, pressupõe a modificação das próprias noções de ciência, natureza e sujeito. Primeiro, porque se cultura e natureza não são separáveis, então a noção de sujeito do conhecimento não pode mais ser pensada em termos de espontaneidade e liberdade; segundo, porque se a natureza tem agora um novo papel, então a ciência da natureza não pode ser separada da ciência do espírito. Que essas implicações nem sempre sejam percebidas tem consequências diretas para os dilemas do pensamento dito pós-moderno.

\section{A nova situação teórica}

A atitude dita pós-moderna, o pensamento pós-moderno ou o pós-modernismo² são os termos aplicados às mudanças ocorridas nas ciências, artes e sociedades tecnologicamente avançadas desde 1950, quando, por convenção, se encerra o Modernismo (1900-1950) (Santos, 1988; D'Agostini, 2003; Mutschler, 2008). Todavia tal movimento ganhou projeção muito além desses campos, penetrando também as dimensões econômicas, políticase mesmo filosóficas. As transformações que possibilitaram a programação tecnocientífica do cotidiano, o advento da sociedade de consumo e da informação, a arte pop, o suposto pósfordismo no mundo do trabal ho, a globalização financeira e dos mercados e a decadência das grandes narrativas filosóficas (Deus, Razão, Verdade...) ganharam todas, em seu conjunto, o epíteto de pós-modernas.

Conforme Santos (1988), essa seria uma época que prefere a imagem ao objeto, a cópia ao original, o simulacro (a reprodução técnica) ao real; há a apologia do hiper-real, do espetacular; não haveria mais diferença entre real e imaginário, ser e aparência, não se acreditaria mais na verdade. Para a pós-modernidade o homem é linguagem; não haveria pensamento, nem mundo, nem homem, sem linguagem, sem algum tipo de reapropriação linguística. ${ }^{3}$ A pós-modernidade é também uma semiurgia, um mundo super-recriado pelos signos. Manipulam-se crescentemente mais signos do que coisas. Assim, na filosofia, o pós-moderno está associado à desconstrução e decadência das grandes ideias, princípios, concepções e instituições ocidentai ${ }^{4}$, defendendo-se a ausência de valores e de sentido para a vida. Mortos estariam os deuses e os grandes ideais do passado; no seu lugar, o homem moderno teria valorizado a arte, a história, o desenvolvimento e a consciência social como pontes para a salvação da vida. Mas ao dar adeus a essas ilusões o homem pósmoderno sabe ou presume que não existe céu nem sentido para a história e, assim, se entrega ao presente e ao prazer, ao consumo e ao individualismo. ${ }^{5} \mathrm{~A}$ apologia pós-moderna diz que esse movimento abala preconceitos, põe abaixo o muro entre arte culta e de massa, rompe as barreiras entre os gêneros e traz de volta o passado (pois os modernos só queriam 
o novo), mesmo que em forma de paródia. Val orizam-se a diferença, a dispersão e considerase a desordem como o substrato fértil da imaginação criativa.

As grandes marcas pós-modernas seriam o pluralismo e o ecletismo, que propõem a convivência de todos os estilos, de todas as épocas, sem hierarquias. ${ }^{6}$ Legitimam-se, desse modo, as múltiplas referências para o agir dos sujeitos no espaço social. Esta seria, ainda segundo Santos (1988), uma das mais importantes diferenças a reter: enquanto na modernidade buscavam-se e se encontravam, com certa facilidade, as identidades fixas e definidas, por meio de representações claras e ordenadas, que funcionavam na base do 'ou' exclusivo (era-se capitalista ou socialista, normal ou louco, culto ou analfabeto; um ou outro, jamais os dois), na pós-modernidade passa-se para uma lógica fundada no 'ou' inclusivo, sendose isto ou aquilo, mas também isto e aquilo. Não há mais identidades definidas, não se distingue o verdadeiro do falso; só há combinações, ecletismos, transições e transações. Com a mistura de estilos, a pós-modernidade é isto e aquilo, não mais oposição, mas justaposição e composição (campo e cidade, barroco e moderno, clássico e contemporâneo, masculino e feminino - unissex/andrógino -, apatia e desenvoltura etc.).

Restam, porém, muitas dúvidas sobre o que significam esses fenômenos e se realmente se pode dizer que a humanidade ultrapassou o ideário moderno, pois as relações entre a pós e a modernidade são prenhes de ambiguidades, derivando daí, talvez, a capacidade de abrangência e o ecletismo da visão pós-moderna e, mesmo, os seus próprios paradoxos, que agora se apresentam quase como um "círculo confuso de autorreferências" (Kumar, 1997).

Por ora essas considerações e caracterizações, embora breves, são suficientes para os propósitos do presente artigo. No amplo espectro do pensamento pós-moderno, qual seria, então, a imagem predominante sobre a natureza? Que el aborações e papéis têm sido atribuídos a essa noção? Para esboçar uma resposta, convém delinear um inventário das principais concepções de natureza a partir e contra as quais se produz o discurso pós-moderno.

\section{Breve inventário das ideias sobre a natureza}

A ideia de natureza como representação do entorno e às vezes do real é tão complexa quanto a ideia de humano e ao longo da história humana modificou-se muitas vezes. Segundo Lenoble (1990), que considera haver não uma 'natureza em si', mas uma 'natureza pensada' que se articula com uma atitude de consciência, a qual, ao se transformar, leva a uma modificação da visão dessa mesma natureza”, há quatro concepções básicas.

A primeira delas teria sido a 'natureza mágica', com suas características animistas e antropomórficas, derivada do pensamento introvertido e essencialmente finalista, em que nada acontece por acaso, mas nada também acontece pelo efeito de leis independentes da história dos homens. Corresponde ao pré-classicismo grego e ao despertar da consciência humana. A natureza e o divino se confundem: Deus é imanente ao natural. A natureza possui vida e consciência, e as vontades dos homens e as das coisas encontram-se numa rede inextrincável, a ligar num mesmo destino homens e coisas, fruto de uma projeção simultânea do psiquismo sobre as coisas e de uma negação da sua alteridade ameaçadora. O homem se achava então entregue ao capricho dos deuses, emblema de forças cegas que 
faziam acontecer os grandes cataclismos naturais (infundindo temor) ou a bonança da fartura (infundindo veneração).

A segunda concepção provém do chamado milagre grego, no dizer de Lenoble, que produz uma visão objetiva e jurídica da natureza, instituída à luz da polis. São então as leis da polis que fornecerão o protótipo das leis da natureza, pois não há mais liberdade sem lei, e a natureza inteira é, desse modo, hierarquizada como a cidade grega, da qual se torna o modelo e justificação. ${ }^{8}$ Com Platão e Aristóteles, o homem passa a perceber a existência de coisas separadas do humano, que existem em si, com movimentos próprios; passa a ver que não existem somente o homem e os seus problemas, que também as coisas são. Há uma associação da natureza com a ordem, que, regida por leis, podia ser compreendida e livrar o homem do jogo do caos. Portanto conhecendo as leis e comportando-se por elas, o homem podia se libertar do acaso. Mas todo esse sistema de pensamento orientava-se por atribuir ao movimento e à ordem das coisas uma hierarquia e uma finalidade, tendo em Deus o princípio ordenador último. A natureza de Platão e Aristóteles, toda ela penetrada de intenções final istas e organizada para a tranquilidade e salvação da al ma, é uma natureza feita para o homem e pelo homem.

Mas a mesma época de 'natureza objetiva' também gerou um pensamento contrário ao finalismo aristotélico: o atomismo. Para os atomistas (Leucipo, Demócrito, Epicuro), a natureza é feita de átomos que não vêm de parte alguma e não vão para parte alguma, num jogo gratuito, sem seguir qualquer vontade nem qualquer intenção. $O$ mundo não significa nada e o homem também é filho do acaso, devendo guardar os desejos para si e não os projetar no mundo exterior. A física, para os atomistas, é a ciência que permite penetrar a natureza para dela expulsar os sortilégios temíveis, concebendo tanto o homem quanto a natureza como coisas, máquinas de sensações e de instintos. Enquanto o aristotelismo perscruta a natureza para descobrir as regras que ela dita ao homem, o atomismo a estuda para se certificar de que ela não prescreve regra nenhuma. Não havendo projeção do desejo, não haveria ordem necessária a seguir. Ao postular uma liberdade absoluta, os atomistas desprezam um cosmo organizado e favorável ao homem, do qual seria necessário captar a ordem que regularia a existência humana. ${ }^{9}$

As visões de natureza elaboradas no período do milagre grego estenderam sua influência por longos séculos, transpondo os limiares da Idade Média. Mesmo com a entrada em cena do cristianismo, houve mais composições do que rupturas na visão sobre a natureza, como o sistema aristotélico-tomista da escolástica. ${ }^{10}$

A terceira concepção corresponde à hegemonia histórica alcançada pelo cristianismo, o qual pensou a natureza como criatura e ordem derivada de uma divindade transcendente (não natural). Somente Deus pode quebrar a ordem natural, e o acontecimento, que é a natureza, seria a exteriorização e a realização de um plano ou pensamento divino.

A quarta concepção emerge no alvorecer do século XVII como essência do Bacon-Projekt, como denominou Schäfer (1993). Começam a tomar forma os movimentos que imprimirão uma outra imagem para a natureza, e conforma-se a 'natureza mecânica', resultante da revolução científica do racionalismo e do lluminismo, com seu construtivismo matemático e determinista. A verdade sobre a natureza reside agora nas experiências matematicamente projetadas e não nos raciocínios sobre as essências. Reeditando-se aspectos do atomismo 
grego, reduz-se a natureza a uma máquina, da qual se podem descobrir as leis de funcionamento e, então, geri-la e colocá-la em funcionamento a serviço dos fins humanos. ${ }^{11}$

Os primeiros físicos mecanicistas ainda procuravam conhecer a natureza, confiantes na sabedoria do Divino Relojoeiro, cujas intenções tentavam desvelar para se colocar como gerentes da 'máquina' de Deus. No século XVIII, já dominando tão bem as alavancas dessa 'máquina', começam a se interrogar sobre a pertinência de atribuir a um Senhor o trabal ho de suas próprias mãos e razão. Postula agora o homem transformar a sua gerência numa tomada de posse em seu próprio nome. $\mathrm{E}$ ao remover o finalismo divino, consuma-se a ruptura com o aristotelismo-tomista. ${ }^{12}$

Essas são, resumidamente, as visões sobre a natureza elaboradas historicamente pelo pensamento ocidental, conforme descritas por Lenoble (1990). Suas considerações finalizam nos dilemas lançados pelo paradigma mecanicista em sua fase mais avan çada, sem especular sobre outra visão, correspondente ao período contemporâneo, a qual poderia ser fruto da ciência relativista ou do pensamento pós-moderno. ${ }^{13}$ Essas reflexões já apontam alguns dilemas importantes, com certa duração histórica, no pensamento sobre as relações entre homem e natureza. Todavia o debate atual, no qual emerge a posição pós-moderna, pode ser descrito como o confronto entre quatro concepções: (1) a natureza como totalidade do que existe e que é descrita pela metodologia científica; (2) a natureza como totalidade do que existe, mas que se abre para diferentes perspectivas que não se reduzem às ciências; (3) a natureza como uma região ou dimensão particular descrita pela ciência; e (4) a natureza como região passível de ser descrita por diferentes perspectivas (Mutschler, 2008). Em geral as posições pós-modernas se orientam pela segunda dessas posições e se contrapõem à primeira. Contudo, Mutschler (2008, p.72) e Schäfer (1993) mostram que na própria argumentação de Latour ou Lovelock recorre-se a conceitos e dados não justificáveis por suas teorias. O que importa, nesse debate, é a localização do humano e o papel que o conceito de natureza exerce na sua autocompreensão.

\section{Uma noção pós-moderna de natureza?}

Fazem parte do cenário cultural pós-moderno as preocupações com a conservação e a deterioração ambiental, condensadas socialmente nos diversos movimentos ecológicos (Vincent, 1995, cap.VIII; Mutschler, 2008; Schäfer, 1993). As implicações e vulgarizações contemporâneas de tais preocupações vêm fazendo com que cada vez mais pessoas se voltem também para a zona rural, o naturismo, a tradição popular e folclórica, a comida natural, o cultivo 'orgânico' de legumes e verduras, as religiões orientais, as reservas e parques naturais, a saúde e a medicina homeopática etc. Para Vincent (1995, cap.VIII), o espectro filosófico que fundamenta esse ecologismo gira ao redor de dois polos matrizes: a tendência que argumenta ser o valor da natureza apenas instrumental, tendo relevância somente para o homem ou uma vez que este a confere; e, de maneira oposta, a tendência da deep ecology, perspectivando um holismo que defende o valor primordial da ecosfera como um todo, em que a natureza não pode ser usada de modo instrumental porque tem valor intrínseco e a humanidade está unida à sua totalidade. ${ }^{14}$ Os argumentos próximos a esse segundo polo tendem a relativizar o homem, removendo-o do estágio central e 
afirmando a sua igualdade ecológica com os demais organismos. Ora, essa crítica ao antropocentrismo encontra sua âncora, em termos pós-modernos, em Nietzsche (1991), em sua desconstrução filosófica que denuncia a morte de Deus e do próprio homem, relativizando-o como medida de todas as coisas. ${ }^{15}$ Se o homem é relativizado em favor da ecosfera (geocentrismo ou ecocentrismo), faz sentido defender a 'conservação da natureza', independentemente dos interesses humanos.

Essa permissividade nietzschiana, que a pós-modernidade abraça com tanto gosto, coloca outro paradoxo que se consubstancia nas noções de equilíbrio e estabilidade em contraposição à adaptabilidade ecológica. Como compatibilizar noções como equilíbrio ou estabilidade (a homeostase ou ten dên cia ao equilíbrio existente em ecossistemas naturais), tão caras às experiências da chamada agricultura alternativa (orgânica, ecológica, biodinâmica etc.), com a noção de adaptação dos ecossistemas ou organismos, nos moldes da experiência relatada por Guattari (1997) ${ }^{16}$ ? Além do mais, essa crença atual num suposto equilíbrio da natureza, ordenadora de diversas práticas agrícolas 'alternativas' e explicativa para cataclismos ambientais advindos de 'desequilíbrios' teve, antes de ganhar argumentação científica, uma base teológica, herança filosófica descartável na pós-modernidade. Como lembra Thomas (1996, p.329):

Foi a crença na perfeição do desígnio divino que precedeu e sustentou o conceito da cadeia ecológica, sendo perigoso remover qual quer um de seus el os. A argumentação do desígnio continha forte implicação conservacionista, pois ensinava que mesmo as espécies aparentementemais nocivas serviam a al gum propósito humano indispensável. No século XVIII, a maior parte dos cientistas e teólogos defendia, coerentemente, que todas as espécies da criação tinham um papel necessário a desempen har naeconomia da natureza.

Também a hipótese-Gaia de Lovelock, que vê a terra como um imenso organismo vivo autorregulador, entra nesse mesmo vórtice paradoxal da adaptação versus equilíbrio. Mesmo que a humanidade polua a biosfera e se envenene, a terra-Gaia poderá continuar se adaptando infinitamente, ainda que haja níveis letais de poluição, extinção de espécies (incluída a humana) ou proteção ambiental e sobrevivência, pois o superorganismo é indiferente (Vincent, 1995). Assim, a argumentação de Gaia não serve ao ecologismo como fundamento contra a poluição ou a favor da subsistência humana, pois não se aceita uma derivação ética da simples observação de um processo natural. Paradoxal mente, de uma postura que se pretendia mais holística, as consequências lógicas lembram por demais aquelas do atomismo. ${ }^{17}$

Jameson (1997), em ensaio instigador sobre as antinomias pós-modernas, argumenta que o 'fim da natureza' (e do rural) seria um dos elementos principais da sociedade pósmoderna. Partindo da premissa de que a 'modernização' da vida está, mesmo que relativamente, completa e que tal processo possibilitou ao fluxo da temporalidade humana, social e histórica correr, como nunca antes, com tanta homogeneidade (globalização), Jameson vê uma pós-naturalidade atual, que reside na 'construção' tecnológica de quaisquer fenômenos e coisas. ${ }^{18}$ Essa nova temporalidade homogeneizadora teria, no urbano, sua matriz de produção da pós-naturalidade, o que estaria hoje também a redefinir a própria noção de urbanidade, pois num mundo pós-moderno, afeito às composições, as antigas oposições balizadoras e identitárias do moderno perdem sentido e eficácia: 
O moderno ainda tem algo a ver com a arrogância da gente da cidade sobre os provincianos, quer se trate do provincianismo dos camponeses, de culturas distintas, colonizadas, ou simplesmente do próprio passado pré-capital ista: aquela satisfação mais profunda de ser absolument moderne se dissi pa quando as tecnologias modernas estão em toda parte, não existem mais províncias e mesmo o passado acaba por parecer mais um mundo al ternativo do que um estágio imperfeito e carente deste (Jameson, 1997, p.26-27).

Porém, no novo estágio globalizado do capital, que permeia o mundo pós-moderno, Jameson (1997) vê a agricultura sofrer a 'desnaturalização' via homogeneização tecnoindustrial ${ }^{19}$, processo emblemático da artificialização, 'fim da natureza'. Mas já desconfia da presença implícita de um paradoxo embrionário, já que "dizer isso é evocar a obliteração da diferença em escala mundial e fornecer uma visão do triunfo irrevogável da homogeneidade espacial sobre quaisquer heterogeneidades que possam ainda ser imaginadas em termos de espaço global" (p.41). Pois a val orização da diferença éo prato do dia no cotidiano pós-moderno, não só na esfera econômica, mas também em termos socioculturais e filosóficos. Afinal, proliferam hoje estudos e reflexões apontando a enorme importância da diferença local, territorial, cultural etc. para o 'desenvolvimento' (e a sustentabilidade). ${ }^{20}$ Mas o que Jameson insiste, na verdade, é em indiciar uma obliteração sistemática do 'natural' na pós-modernidade em geral, que não se ilustraria meramente na reorganização da agricultura tradicional em produção industrial, mas também na lúcida consciência dessa "era de que identidades etradições, longe de serem naturais, são 'construídas'" (p.57). ${ }^{21}$ E ao mesmo tempo, tal processo tem rebatimento na dissolução dos próprios limites da cidade tradicional e do urbano clássico, pois se diluem oposições para se acreditar em composições ${ }^{22}$, dissolvendo-se supostas 'fronteiras' entre o rural eo urbano. Acompanhemos, portanto, o fechamento desse raciocínio, conduzido pelo próprio Jameson (p.42):

O desaparecimento da Natureza - a mercantilização do campo e a capitalização da própria agricultura em todo o mundo - começa agora a desgastar o seu outro termo, o que antes era o urbano. Como o sistema mundial de hoje ten de a um enorme sistema urbano - a ten dência a uma modernização cada vez mais completa prenunciava justamente isso, o que, no entanto, ratificou-se e surgi u de manei ra in esperada pel a revolução das comuni cações e suas novas tecn ologias ... - , a própria concepção de cidade e do urbano clássico perde sua significação e parece não mais oferecer nenhum objeto de estudo delineado com precisão, nenhuma real idadeespecificamentediferenciada. Em vez disso, o urbano se torna o social em geral eambos se constituem e se perdem em um global que não é real mente o seu oposto (como era na sua forma antiga), mas al go como o seu alcance externo, o seu prolongamento em um novo tipo de infinidade. ${ }^{23}$

Porém, paradoxalmente, o desaparecimento da natureza em sua forma tradicional como espaço social, onde até mesmo o campo, 'essencialmente provinciano', desaparece, torna-se estandardizado; pode escutar a mesma linguagem, ver os mesmos programas, consumir os mesmos bens que a urbe - também estimulou o retorno de outro 'tipo' de natureza. É obrigatório observar, diz Jameson, quea pós-modernidade étambém o momento de uma série de notáveis revivescências contundentes da natureza - como atestam os diversos fenômenos ligados ao ecologismo - justamente numa configuração em que predominam, nas posições ideológicas e filosóficas contemporâneas, o antifundamentalismo e o 
antiessencialismo. ${ }^{24} \mathrm{Em}$ tal panorama, essa revivescência da natureza constitui uma antinomia fundamental da pós-modernidade.

\begin{abstract}
se, por um lado, a sua redescoberta e reiteração de seus limitesépós-moderna na medida em que repudia o modernismo da modernização e do ethos produtivista queacompanhou um momento anterior do capital ismo, por outro lado, el a devetambém recusar igual mente o prometeanismo de qual quer conceito de Natureza em si, do Outro na história humana, como al go de al guma maneira construído pel o homem. Como pode, então, o antifundamentalismo coexistir com a apaixonada revivescência ecológica do sentido de Natureza constitui um mistério essencial em cujo cerneeu suponho existir uma antinomia fundamental do pós-moderno; não tenho dúvidas de queisso éfato e pode-se observar essa coexistência ativa em toda parteà nossa volta (Jameson, 1997, p.58; grifosnossos).
\end{abstract}

Ao mesmo tempo, há uma segunda questão evocada pela palavra natureza: em que magnitude sua noção, de alguma maneira, abrange necessariamente um conceito de 'natureza humana' (como alertava Lenoble), que pode não ser explicitado como tal, mas que pode e mesmo deve estar implícito no conceito simultâneo e recorrente de limites, o qual, como coloca Jameson (1997), é muito difícil de separar de um ethos ecológico. E esses limites estão hoje a desafiar a crença na capacidade dos homens de mudarem seu atual 'estágio de vida' por meio de movimentos inspirados em al guma 'práxis coletiva'. Jameson finaliza enunciando a perplexidade que parece a todos invadir, quando confrontados com essa antinomia pós-moderna sobre a natureza:

\begin{abstract}
Assim éque o fim do modernismo vem acompanhado não apenas do pós-modernismo, mastambém do retorno da consciência da natureza em ambos os sentidos: ecologicamente, nas condições deploráveis em que a busca tecnológica de lucro deixou o planeta, e, humanamente, numa desilusão com a capacidade dos povos demudar, agir ou conseguir qualquer coisa substantiva em termos de uma práxis coletiva. ... Devemos, portanto, continuar nos surpreendendo com a coexistência desses doismovimentos aparentemente incompatíveis na nossa era: um implacavel mente hostil aos remanescentes naturaise à sobrevivência de quaisquer formas de naturalidade, o outro por demais receptivo a um renovado senso de natureza e limite, por mais que isso se baseie em derrota e desil usão (p.62-63).
\end{abstract}

Ora, essa atitude bipolar pode ser resolvida apenas com o reconhecimento do natural como parte imanente do humano, ou seja, com a elisão da separação entre cultura e natureza, imposta por uma autocompreensão histórica do espírito e da cultura como antinaturais e da natureza como antiespiritual. Para tanto, é necessário superar a visão atômica, mecanicista e determinista da natureza, como também a visão idealista e subjetivista do humano.

A tentativa de superação, todavia, representada pelos ditos pós-modernismos sob as rubricas pragmatismo, pós-estruturalismo, historicismo, linguisticismo, no dizer de Sokal (2006, p.2), configura uma atitude intelectual marcada por certa rejeição da tradição racionalista do lluminismo, por um discurso teorético desconectado de qualquer teste empírico e por um relativismo cultural e cognitivo que enxerga na ciência apenas uma 'narração', um mito ou uma construção social, entre muitas outras. As oscilações pósmodernas em relação à natureza, em geral associadas a críticas fatalistas à ciência, que 
solapam qualquer pretensão de validade, apenas reforçam a dúvida aberta por Sokal quanto à aproximação com a pseudociência. Afinal, a recusa de qualquer vínculo da cultura e do discurso com sua base natural é o primeiro passo para a superstição e para o obscurantismo.

\section{Natureza, técnica e humanidade}

Fato é que o apelo e fascínio atuais da ideia de natureza são efeitos de uma outra contraposição ainda mais instigante, aquela entre a autoconstituição do humano e o caráter necessário da técnica e do artifício. Pois são justamente o caráter excessivo da técnica e o pré-domínio dos aparatos técnicos, em todas as esferas da cultura hodierna, que fazem brilhar a sedução da vida tão somente natural. Uma imagem pós-moderna da natureza talvez possa ser buscada nas reflexões que tentam atualizar o estatuto da tecnociência, o atual instrumento humano privilegiado de relação e contato com a 'natureza'. Tal substrato apresenta-se nas reflexões de pensadores como Souza Santos, Serres, Morin, Prigogine e Stengers. Tomadas em conjunto, suas contribuições podem delinear interfaces com novos e revigorados contornos, apresentando a natureza como processo complexo e singular. Assim, ganha legitimação a apologia da diferença em contraposição ao que seria universal no ideário moderno. O caráter antinômico da referência à natureza reflete o caráter incongruente da própria imagem do humano constituída pela retomada e revivescência de concepções divergentes de natureza.

O que procuramos mostrar aqui é que o caráter paradoxal (e até antinômico) da ideia de natureza, no pensamento atual, deve-se a irresoluções mais profundas do que à simples contraposição entre social e natural ou cultura e natureza, pois tem suas raízes nas próprias contraposições e dissociações que perfazem a autocompreensão do humano. A pré tensão do espírito como antinatural está preservada na mentalidade pós-moderna. Em grande medida, trata-se do dogma legitimador do próprio objeto das ciências humanas contra as ciências naturais. Entretanto, as ciências humanas apenas são possíveis ali onde se reconhece o espírito, a cultura e o social como objetos dados, como tendo uma dada natureza. Levar em conta tal pensamento talvez contribuísse mais para avançarmos em direção a uma concepção de natureza e de ciência que, como lembram ainda Prigogine e Stengers (1997), não implicaria fazer os seres humanos se sentirem estranhos no mundo em que habitam e que buscam conhecer.

\section{NOTAS}

1 "Instinto e razão, marcas de duas naturezas"(Pascal, 1979, §344); “O pensamento faz a grandeza do homem" (§346); “O homem não passa de um caniço pensante. ... Toda a nossa dignidade consiste, pois, no pensamento (§347)"; “Toda dignidade do homem está no pensamento" (§365).

2 Para os fins deste artigo, não diferenciamos pós-modernidade, pós-modernismo, pós-moderno, pósindustrial, hipermodernidade, embora informados das suas nuanças e implicações. Tomamos aqui as caracterizações mais frequentes na literatura sobre o que seria um pensamento e um estilo de vida sociais contemporâneos, que se propõem ou se colocam além dos cânones da modernidade tal como genericamente difundida no mundo ocidental.

${ }^{3}$ Conforme também Bruzzi (1988) e Anderson (1999). 
${ }^{4}$ Deus, Ser, Razão, Sentido, Verdade, Totalidade, Ciência, Sujeito, Consciência, Produção, Estado, Revolução, Família - Kurz (2003) sugere que esses conceitos estão na base dos dilemas entre modernos e pós-modernos.

${ }^{5}$ Sendo a pós-modernidade o declínio das grandes filosofias explicativas, como o cristianismo (e sua fé na salvação), o lluminismo (com sua crença no progresso e na ciência), e o marxismo (com sua aposta na sociedade comunista), étambém muito comum invocar Nietzsche como o primeiro filósofo a desconstruir os valores ocidentais supremos, projetados para acalmar a angústia ou justificar a existência humana. Conforme Santos (1988, p.74), ele teria fornecido importantes argumentos para o discurso pós-moderno (numa suposta vertente anti-humanista), ao abalar os três pilares da cultura ocidental: o cristianismo Fim (garantidor de um sentido existencial), a ciência - Unidade (certeza de um universo cognoscível) e o racionalismo - Verdade (o alcance da real existência das coisas). Voltaremos mais adiante a Nietzsche e suas contribuições e relações com os pensamentos ditos pós-modernos.

${ }^{6}$ Também Jameson (1997, p.12) defende que o ecletismo e o pluralismo estão entre as características principais da pós-modernidade. Daí a imagem do pós-moderno como uma grande nebulosa, volátil e disforme, em que tudo cabe e que a tudo envolve.

7 “'A definição perpetuamente ambígua do 'natural', simultaneamente ordem das coisas e hábito social, faz-nos compreen der que toda a mudança grave da ordem humana é, ao mesmo tempo, uma alteração da Natureza" (Lenoble, 1990, p.159).

${ }^{8}$ Uma representação coerente do mundo pressupõe uma sociedade organizada: o Cosmos de Aristóteles seguiu há 150 anos as leis de Sólon. “E quando Aristóteles exige ao Estado que 'reproduza' a hierarquia da Natureza, constrói a Natureza segundo o modelo da cidade grega. O fenômeno de projeção é aqui evidente e inegável" (Lenoble, 1990, p.67; grifos do autor; ver também p.54-55).

${ }_{9}^{9}$ Numa natureza concebida dessa maneira, o homem perderia, por sua vez, sua posição de centro e fim. Lenoble (1990) defende, a propósito, que há muitos pontos de contato entre o atomismo antigo e o mecanicismo de Descartes e Bacon. Afirma que a tomada de posição do atomismo perante o mundo “significa a reivindicação pelo homem de uma liberdade absoluta perante as coisas, que ele 'pulveriza' já com tanta resolução como aquela que os mecanicistas do século XVII porão em matematizar a natureza. E esta interminável demora que se vai esten der durante a maior parte da humanidade histórica, entre esta primeira visão do mundo e o mecanicismo que será a reedição dela, essa demora que parece aparentemente inexplicável, deve ter um sentido" (p.86; ver também nota 104, p.122-123). Ao tentar explicar esse sentido, Lenoble argumenta que o homem não teria ainda se habituado a essa liberdade, tendo Demócrito chegado um pouco cedo demais, pois sua natureza amorfa não pregava lei nenhuma, e o sucesso do aristotelismo, ao restringir o mundo à medida do homem, pode ser atribuído à recusa do homem em resignar-se a ser filho do acaso.

$10 \mathrm{O}$ atomismo, logicamente, não foi aceito pela Igreja. Ambos, o aristotelismo e o cristianismo da escolástica, acreditavam num finalismo para o movimento e a ordem hierárquica das coisas. Todavia, há no cristianismo uma inferência mais antropocêntrica para o sentido de natureza, acreditando-se que tudo foi criado por Deus para o dispor do homem, seu filho dileto e imagem próxima. Esse elemento não apareceria em Aristóteles (Lenoble, 1990, especialmente nota 83).

${ }^{11}$ O mecanicismo, segundo Lenoble (1990, p.260), "comporta uma nova definição do conhecimento, que já não é contemplação mas utilização, uma nova atitude do homem perante a Natureza: ele deixa de a olhar como uma criança olha a mãe, tomando-a por modelo; quer conquistá-la, tornar-se 'dono e senhor' dela".

12 Como afirma Almeida (1995, p.117), esse ponto de ruptura do mecanicismo encontra-se justamente "na noção de movimento sem finalidade, movimento cujo único objetivo é mover-se, avançar sempre, daí o 'progresso' e, mais recentemente, o 'desenvolvimento', 'religiões' da atualidade". Como vemos, as observações de Lenoble (1990) sobre os pontos de contato entre o antigo atomismo grego e o mecanicismo parecem bem pertinentes.

${ }^{13} \mathrm{O}$ que se compreende, pois sua obra sobre a natureza foi escrita durante a década de 1950 e ele morreu em 1959 deixando-a parcialmente inacabada. No entanto, Zaidán (1995), ao tematizar a relação entre homem e natureza, consi dera que existem quatro grandes épocas culturais: a primeira, da relação mimética do humano com a natureza - correspondendo à 'natureza mágica' de Lenoble; a segunda, da relação amorosa, no período da filosofia grega pré-aristotélica; a terceira, da relação instrumental, que teria sido inaugurada pela metafísica aristotélica e atualizada em toda a sua plenitude pela filosofia moderna; e a quarta e última, correspondendo à época contemporânea e pós-moderna, da relação de simulacro, que estaria levando a extremos as consequências do próprio pensamento moderno, no qual “o sujeito/ 
trabalho é substituído pela linguagem, pelo símbolo, por uma economia política da significação. Aí o conceito de uma natureza dessubstancializada e transformada num mero substrato vazio à disposição dos caprichos humanos é trocada pelo de um simulacro (mais que perfeito) hiper-realizado do mundo. Aqui, opera-se uma dupla elisão: a do sujeito e a do objeto, e a única coisa que sobrevive é a linguagem, um sistema de signos sem significação. O simulacro expropria do homem e da natureza todas as suas relações, interpondo-se entre um e outro" (p.128).

${ }^{14}$ Como exemplo, a hipótese-Gaia, de Lovelock, estaria mais próxima dessa tendência (Vincent, 1995, p.221), como também as éticas não antropocêntricas de Taylor (1989) e Rolston (1981).

${ }^{15}$ Recorremos também a Braida (1992) para a leitura interpretativa das ideias de Nietzsche aqui expostas. Lembramos novamente tratar-se de um filósofo-chave para o discurso pós-moderno.

${ }^{16} \mathrm{Um}$ pequeno polvo que nadava feliz num tanque de águas poluídas da baía de onde fora retirado e morreu ao ser colocado num tanque com água 'limpa'.

${ }^{17}$ Como aponta Vincent (1995, p.223): “O mais grave de tudo isso é a dificuldade de perceber qual a noção de natureza da abordagem intrínseca e de sua ligação com a teoria de Gaia. Se os homens são parte da natureza, na posição 'indiferente' de Gaia, então provavel mente somos livres, assim como todos os outros animais, para utilizar o mundo à nossa volta. Se é da nossa natureza explorar e se portanto nos destruirmos, o universo não ligará a mínima".

18 “Nossas estações do ano são produtos pós-naturais e pós-astronômicos, da televisão e da mídia, triunfalmente artificiais por meio da força das imagens do canal da National Geographic ou da meteorologia - simulam ritmos, antes naturais, para a conveniência comercial" (Jameson, 1997, p.32).

19 "A agricultura - culturalmente distinta e identificada na superestrutura como o Outro da Natureza torna-se agora uma indústria como qualquer outra, e os camponeses, simples operários cujo trabalho é classicamente mercantilizado em termos de equivalências de valor" (Jameson, 1997, p.40).

20 Para uma discussão sobre o modo como a globalização, por meio de distintas e específicas demandas, convive com a valorização da diferença dos localismos e regionalizações e a estimula, ver Featherstone (1996), Ortiz (1996), Yáñez (1998), Souza (1997), Froehlich (1999), entre outros.

${ }^{21} \mathrm{O}$ 'recorte' que conta a história de determinada região ou localidade para produzir mais atratividade (turismo rural, turismo ecológico, turismo histórico etc.), elencando aspectos folclóricos, reconstituição de produtos, trabalhos, tradições, jogos e cantares, comidas típicas, entre outros, pode ser encarado, nesse sentido, como 'construção'. Ver, a respeito, Champagne (1977), Cavaco (1996), M ormont (1996), Mathieu (1996) e Froehlich (2003), entre outros.

22 “Nos territórios de forte conteúdo de ciência, tecnologia e informação não há mais sentido contrapor a cidade ao campo, o urbano ao rural, nem tampouco insistir na distinção entre os clássicos setores da atividade econômica" (Rodrigues, 2004, p.33).

${ }^{23}$ Gilberto Freyre (1982, p.117-118), ao comentar estilos de desenvolvimento urbanista e regional, já tivera insight pertinente sobre os elementos pós-modernos articulados e presentes na sua proposta de rurbanização (como, por exemplo, a valorização do passado, do antigo, do arcaico compondo e justapondo com o moderno, o tecnológico, o cosmopolita): “Tanto uma orientação como a outra, a Regionalista francesa e a do Recife - a ela pioneiramente anterior - prestam-se a ser acusadas de romanticoidemente arcaizantes e anti-industriais e antiurbanas, através de suas valorizações de valores regionais e tradicionais, por muitos associados principal mente a vivências arcaicamente rurais. Mas serão válidas essas acusações? Serão as formas rurais de vivência, necessariamente antiprogressistas ou antimodernas, por constituir opostos a formas urbanas e urbano-industriais? Ou haverá em atitudes supostamente arcaizantes, antecipações de formas pós-modernas de equilíbrio ou de contemporização entre valores urbanos transferíveis a áreas rurais e desejos, da parte até de jovens dos nossos dias, de desfrutarem de um convívio com águas, árvores, plantas, animais rurais, impossível dentro dos muros estritamente urbanos?. Não será possível pós-modernamente conciliar-se experiências telúricas com o gozo de modernas conveniências urbanas?" .

${ }^{24}$ Jameson (1997, p.58) comenta: “A natureza é, então, com toda a certeza, o grande inimigo de qualquer antifundamentalismo ou antiessencialismo: termo final e conteúdo de qualquer essência ou axioma, de qualquer pressuposição última ou metafísica, de qualquer limite ou destino que possa ser colocado. Dispensar os últimos remanescentes da natureza e o natural enquanto tal é, certamente, o sonho secreto e o desejo de todo o pensamento contemporâneo ou pós-contemporâneo, pós-moderno - mesmo sendo um sonho que este último sonha com uma certa ressalva secreta de que a 'natureza', para começo de conversa, nunca existiu mesmo". 


\section{REFERÊNCIAS}

ALMEIDA, Ângela Mendes de.

A 'natureza' e seus múltiplos usos. Estudos Sociedade e Agricultura, Rio de Janeiro, n.4, p.113-125. 1995.

ANDERSON, Perry.

As origens da pós-modernidade. Rio de Janeiro: Zahar. 1999.

BRAIDA, Celso Reni.

Os limites do intelecto: ensaio acerca da crítica do conhecimento na obra tardia de F. W. Nietzsche. Dissertação (M estrado) - Programa de Pós-graduação em Filosofia, Universidade Federal do Rio Grande do Sul, Porto Alegre. 1992.

BRUZZI, Hizina.

A cultura do simulacro. São Paulo: Paulinas. 1988.

CAVACO, Carminda.

Turismo rural e desenvolvimento local.

In: Rodrigues, Adyr. (Org.). Turismo:

desenvolvimento local. São Paulo: Hucitec. p.94-121. 1996.

CHAMPAGNE, Patrick.

La fête au village. Actes de la Recherche, Paris, n.17-18, p.72-83. 1977.

D'AGOSTINI, Francesco.

Analíticos e continentais: guia à filosofia dos últimos trinta anos. São Leopoldo: Editora Unisinos. 2003.

FEATHERSTONE, Michael.

Localismo, globalismo e identidade cultural. Sociedade e Estado, Brasília, v.11, n.1, p.9-42. 1996.

FREYRE, Gilberto.

Rurbanização: que é?. Recife: Ed. Massangana; Fundação Joaquim Nabuco. 1982.

FROEHLICH, José Marcos.

A (re)construção de identidades e tradições: o rural como tema e cenário. Antropolítica, Niterói, n.14, p.117-132. 2003.

FROEHLICH, José Marcos.

O local na atribuição de sentido ao desenvolvimento. Textos CPDA, Rio de Janeiro, n.7, p.3-21. 1999.

GUATTARI, Felix.

As três ecologias. 6.ed. Campinas: Papyrus. 1997.

HEGEL, Georg Wilhelm Friedrich.

Lecciones sobre la filosofía de la história universal. Madrid: Alianza Editorial. 1989.

JAMESON, Fredric.

As sementes do tempo. São Paulo: Ática. 1997.
KANT, Immanuel.

Crítica da razão pura. São Paulo: Abril Cultural. 1980.

\section{KUMAR, Krishan.}

Da sociedade pós-industrial à pós-moderna. Rio de Janeiro: Zahar. 1997.

KURZ, Robert.

Negative ontologie, Die Dunkelmänner der Aufklärung und die Geschichtsmetaphysik der Moderne. Krisis, Nürnberg, n.26, p.13-42. 2003.

LENOBLE, Robert.

História da ideia de natureza. Lisboa: Edições 70. 1990.

MATHIEU, Nicole.

Rural et urbain: unité et diversité dans les évolutions des modes d'habiter. In: Jollivet, Marcel; Eizner, Nicole. (Org.). L'Europe et ses campagnes. Paris: Presses des Sciences Politiques. p.187-215. 1996.

MOREIRA, Roberto José.

Ruralidades e globalizações: ensaiando uma interpretação. In: Moreira, Roberto José (Org.). Identidades sociais: ruralidades no Brasil contemporâneo. Rio de Janeiro: DP\&A p.15-40. 2003.

MORMONT, Marc

Le rural comme catégorie de lecture du social. In: Jollivet, Marcel; Eizner, Nicole. (Org.).

L'Europe et ses campagnes. Paris: Presses des Sciences Politiques. p.161-176. 1996.

MUTSCHLER, Hans-Dieter. Introdução à filosofia da natureza. São Paulo: Edições Loyola. 2008.

NIETZSCHE, Friedrich Wilhelm.

Obras incompletas. São Paulo: Nova Cultural. 1991.

ORTIZ, Renato.

Anotações sobre a mundialização e a questão nacional. Sociedade e Estado, Brasília, v.11, n.1, p.43-56. 1996.

PASCAL, Blaise.

Pensamentos. 2.ed. São Paulo: Abril Cultural. 1979.

PRIGOGINE, Ilya; STENGERS, Isabelle. A nova aliança. 3.ed. Brasília: Editora UnB. 1997.

REDCLIFT, Michael.

Entrevista. Agricultura Sustentável, Brasília, n.1-2, p.5-12. 1996.

RODRIGUES, Adyr.

Turismo eco-rural: interfaces entre o ecoturismo 
e o turismo rural. In: Almeida, Joaquim; Froehlich, José Marcos; Riedl, Mário (Orgs.). Turismo rural e desenvolvimento sustentável. 4.ed. Campinas: Papyrus. p.85-96. 2004.

ROLSTON, Holmes.

Values in nature. Environmental Ethics, Denton, n.3, p.113-128. 1981.

SANTOS, Jair Ferreira dos.

O que é pós-moderno. 5.ed. São Paulo: Brasiliense. 1988.

SCHÄFER, Lothar.

Das Bacon-Projekt. Frankfurt: Suhrkamp. 1993.

SOKAL, Alan.

Pseudoscience and postmodernism: antagonists or fellow-travelers? In: Sokal, Alan.

Archaeological fantasies: how

pseudoarchaeology misrepresents the past and misleads the public. London: Routledge. p.286-361. 2006.

SOUZA, Marcelo Lopes de. Algumas notas sobre a importância do espaço para o desenvolvimento social. Território, Rio de Janeiro, n.3, p.13-35. 1997.
TAYLOR, Paul W.

Respect for nature: a theory of environmental ethics. New Jersey: Princeton University Press. 1989.

THOMAS, Keith.

O homem e o mundo natural. São Paulo:

Companhia das Letras. 1996.

VIDEIRA, Antonio Augusto Passos.

Natureza e ciência moderna. Ciência\&Ambiente, Santa Maria, n.28, p.121-134. 2004.

VINCENT, Andrew.

Ideologias políticas modernas. Rio de Janeiro: Zahar. 1995.

YAÑEZ, Clemente Navarro.

Globalización y localismo: nuevas oportunidades para el desarrollo. Revista de Fomento Social, Córdoba, n.53, p.31-46. 1998.

ZAIDÁN, Michel.

Fundamentos sociofilosóficos da questão ambiental. Estudos Sociedade e Agricultura, Rio de Janeiro, n.4, p.126-129. 1995.

\section{uUuUUU}

